\title{
Guided User Research Methods for Experience Design-A New Approach to Focus Groups and Cultural Probes
}

\author{
Anne Elisabeth Krueger ${ }^{1, * \mathbb{D}}$, Kathrin Pollmann ${ }^{1}$, Nora Fronemann ${ }^{1}$ and Beatrice Foucault ${ }^{2}$ \\ 1 Fraunhofer Institute for Industrial Engineering IAO, 70569 Stuttgart, Germany; \\ kathrin.pollmann@iao.fraunhofer.de (K.P.); nora.fronemann@iao.fraunhofer.de (N.F.) \\ 2 OrangeTM, 22300 Lannion, France; beatrice.foucault@orange.com \\ * Correspondence: anne-elisabeth.krueger@iao.fraunhofer.de
}

Received: 29 May 2020; Accepted: 22 July 2020; Published: 26 July 2020

\begin{abstract}
Many companies are facing the task for radical innovations-totally new concepts and ideas for products and services, which are successful at the market. One major factor for success is a positive user experience. Thus, design teams need, and are challenged to integrate, an experience-centered perspective in their human-centered design processes. To support this, we propose adjusted versions of the well-established user research methods focus groups and cultural probes, in order to tailor them to the specific needs and focus of experience-based design, especially in the context of solving "wicked design problems". The results are experience focus groups and experience probes, which augment the traditional methods with new structuring, materials, and tasks based on the three principles experience focus, creative visualization, and systematic guidance. We introduce and describe a two step-approach for applying these methods, as well as a case study that was conducted in cooperation with a company that illustrates how the methods can be applied to enable an experience-centered perspective on the topic of "families and digital life". The case study demonstrates how the methods address the three principles they are based on. Post-study interviews with representatives of the company revealed valuable insights about their usefulness for practical user experience design.
\end{abstract}

Keywords: user experience; user research; experience focus groups; experience cultural probes; building ideas; design thinking; user-centered design; design for experience

\section{Introduction}

With the proceeding digitalization, many companies need to reinvent themselves as well as their product and service portfolio in order to stay competitive in the market. Thus, they are facing the task of radical innovation-totally new concepts and ideas for products and services, which are successful in the market. One major factor for success is a positive user experience. It has been shown that users prefer products and services that promote positive experiences [1,2]. Positive experiences seem to foster long-term usage and product bonding [3]. It is assumed that users experience products and services along two different dimensions [4]: hedonic and pragmatic qualities. Hedonic qualities refer to affective components of a product or service, e.g., the enhancement of a person's psychological wellbeing. Pragmatic qualities comprise the functionality and usability of the product or service. Thus, it is no longer sufficient for companies to develop just functional products and services that solve problems effectively and efficiently. Instead, it seems essential to design positive experiences for the user. Products and services should encourage an increase in well-being and happiness besides making life easier. However, many companies and their design teams rather work with a usability-mindset [5]. 
Those are challenged and in need for guidance and support in order to integrate hedonic aspects into their human-centered design processes [6]. Furthermore, creating radical innovations with a focus on hedonic qualities opens a variety of possible design paths for a users' positive experience with a product or service. To address this multiplicity, open, wide, and rather undefined questions can be set as starting points for the human centered-design process, so-called "wicked problems" [7].

To design products and services that can enable positive experiences, it is important to first establish a deep and rich understanding of the user group and the context of use. Thus, we promote a two-step approach for conducting user research for the "wicked problems". As Morgan [8] puts it: "This strategy has the advantage of first identifying a range of experiences and perspectives, and then drawing from that pool to add more depth where needed." Therefore, the first step is aimed at gathering controversial insights about the "wicked problem" from multiple users' experiences. This is done to obtain an overview of potentials for positive experiences and implications for further in-depth user research. The results of the first step are used as a base for redefining, specifying, and narrowing down the user research questions and the definition of relevant user groups for the second step. The aim of the second step is then to develop a deep and rich understanding of specific user groups and their requirements regarding positive experiences. In addition, the second step is meant to gain insights about possible interdependencies, e.g., with context and time, which are relevant factors when designing for a positive user experience [9].

\subsection{Existing User (Experience) Research Methods}

There are several traditional user research methods, e.g., interviews, focus groups, surveys [10], and contextual inquiries [11] (see Table 1) that could be used for realizing the two described steps. However, these approaches often lack the focus on the hedonic aspects of the users' experiences.

Some attempts have been made to develop user research and design methods with a clear focus on the user experience. However, some of them presuppose the understanding of rather abstract psychological models (need cards [12], emotion granularity cards [13], and wellbeing determinant cards [14]) and scientific methods (UX Concept Exploration [3], the day reconstruction method [15]), which are often not commonly known in the companies' design teams. The few methods, which do not require fundamental psychological understanding, are either only applicable for specific experience contexts (e.g., work environments) (experience categories, experience potential analysis [16-19]) or rather focus on the survey of individuals and do not allow for, e.g., controversial group discussions, such as the experience interview [20]. This, however, seems relevant in order to approach the inherent variety of a "wicked problem" (see step one above). Additionally, the stated methods merely build on the users' verbal or written articulation of their experiences. Since mental models of users and designers about the users' experiences can differ [21], and language can have multiple meanings, the resulting products and services may not be able to invoke a positive experience for the users. However, diary documentation (e.g., the day reconstruction method [15]) that could provide a survey of the long-term and contextual factors of the users experience' for step two are merely based on the users' written or verbal articulation and not, e.g., on the visual expression of their experiences. Thus, they are more likely prone to misunderstanding of mental models. Cultural probes [4] could contribute a creative drive for visualization here. However, they are missing guidance for a systematic survey of experiences. Instead, the results serve as a creative inspiration for designers. The generative co-creation [22] methods embrace this issue. However, they are missing a long-term survey approach and an explicit focus on hedonic aspects of the users' experience. 
Table 1. Deficiencies of existing user research methods.

\begin{tabular}{|c|c|c|}
\hline Method & Description & Deficiencies \\
\hline $\begin{array}{l}\text { Traditional user research } \\
\text { methods e.g., [10] }\end{array}$ & E.g., focus groups, interviews, surveys, ethnographic methods. & $\begin{array}{l}\text { Traditional usability methods have their origin in social } \\
\text { sciences and/or classic usability-engineering and, thus, haven } \\
\text { not an inherent focus on the users' experience. }\end{array}$ \\
\hline Contextual Inquiries [11] & $\begin{array}{l}\text { Field interviews conducted with users, e.g., in their workplaces while they } \\
\text { work. Thereby the user researchers are observing and inquiring into the } \\
\text { users' perspective. }\end{array}$ & $\begin{array}{l}\text { The contextual inquiries are traditionally designed to analyze } \\
\text { the users', activities, tools, and flows at their workplace. The } \\
\text { primary focus is on understanding the processes and the } \\
\text { requirements by obtaining information that are not always } \\
\text { conscious to the user. }\end{array}$ \\
\hline Need Cards [12] & $\begin{array}{l}\text { The need cards are based on the user experience model }[23,24] \text {, which sets } \\
\text { the fulfillment of basic human needs as base for a positive UX. The need } \\
\text { cards contain a brief description as well as typical feelings, visualizations } \\
\text { and quotes for seven relevant psychological needs. The need cards are } \\
\text { created to provide orientation and inspiration when designing products } \\
\text { that aim at evoking positive experiences in the user. }\end{array}$ & $\begin{array}{l}\text { The need cards do not involve guidance on how to apply them, } \\
\text { e.g., in user experience research, except for just reading them. } \\
\text { Therefore, it is possible that, when need cards are solely used, } \\
\text { the needs may still appear abstract and theoretical, especially in } \\
\text { design teams with a predominant usability mindset. }\end{array}$ \\
\hline
\end{tabular}

The method consist of three phases: I. Concept briefing (users get to know

UX Concept Exploration the product or service concept), II. Field phase (users imagine the usage of the presented concept, evaluate and extend it regarding basic user needs),

III. Analysis workshop and expert evaluation regarding the fulfillment of basic needs by the promoted concept.

Narrative-Interview to prompt users about positive experiences and specific aspects regarding those. The Experience Interview can be

Experience Interview [20] conducted in two ways: prompting the user openly about positive experiences in specific contexts.

The execution of UX concept exploration requires a

fundamental understanding of the psychological needs model for user experience. Furthermore, it requires UX experts for the evaluation of the resulting ideas and concepts.

The experience interview is designed to prompt individual users about their experiences. Thus, it does not allow for, e.g., controversial group discussions as required for step 1 of our Experience categories are a methodology aimed at understanding existing
and creating new positive experiences. The categories describe aspects of

Experience Categories $[16,18,19]$ positive experiences for specific contexts, which can be, e.g., used in analysis workshops or as a starting points for ideation. written articulation of the users' experiences.

\section{The experience categories exist only for specific contexts} (e.g., work environments and kitchens). 
Table 1. Cont.

\begin{tabular}{lll}
\hline \multicolumn{1}{c}{ Method } & \multicolumn{1}{c}{ Description } \\
\hline $\begin{array}{l}\text { Experience Potential } \\
\text { Analysis [17] }\end{array}$ & $\begin{array}{l}\text { The experience potential analysis enables a creative process aimed at the } \\
\text { identification of potentials for a positive user experience design. The } \\
\text { method and its creative process is based on the experience categories [16]. }\end{array}$ & $\begin{array}{l}\text { The experience potential analysis exists only for specific } \\
\text { contexts (e.g., work environments and kitchens). }\end{array}$ \\
\hline $\begin{array}{l}\text { The day re-construction } \\
\text { method [15] }\end{array}$ & $\begin{array}{l}\text { The participants construct a short diary of the previous day. Thereby they } \\
\text { are asked to divide this day into specific episodes (e.g., commuting to } \\
\text { work) and estimate their durations. Then, the participants are questioned } \\
\text { regarding specific aspects about their experience during the episode. }\end{array}$ & $\begin{array}{l}\text { Merely builds on the users' verbal or written articulation of } \\
\text { their experiences. }\end{array}$ \\
\hline Co-creation Methods [15] & $\begin{array}{l}\text { The participants are enabled to immerse in and express their experiences } \\
\text { during, e.g., a workshop session with the aid of visual materials. }\end{array}$ & $\begin{array}{l}\text { The co-creation methods are missing systematic guidance for } \\
\text { longlicitly on the survey of hedonic aspects of the users' } \\
\text { experience. }\end{array}$ \\
\hline Cultural Probes [26,27] & $\begin{array}{l}\text { Cultural probes enable the users to record their answers to a given } \\
\text { research topic with artifacts such as postcards, cameras and diaries. }\end{array}$ & $\begin{array}{l}\text { The cultural probes are missing merely a guidance for a } \\
\text { systematic survey of experiences. Instead, the results serve } \\
\text { rather as a creative inspiration for designers. }\end{array}$ \\
\hline
\end{tabular}


As argued above, there is no existing user (experience) research method that fully addresses all of these aspects. Thus, there is a need to extend the existing methodological portfolio in user (experience) research with new (combinations) of methods, in order to enable a focus on hedonic aspects and experience-centered design. In summary, in order to be applicable for companies and to address both steps described above, user research methods have to address the following requirements:

1. Clear focus on user experience

2. Enable visual articulation of experiences

3. Provide guidance for practical application e.g., in companies' design teams

\subsection{Augmentation of Existing User Research Methods with Focus on Experience, Guidance, and Creative Expression}

To address the "wicked problems" within user experience research, we propose to build on existing, well-established user research methods (see Table 1) and enrich them by including hedonic aspects of user experiences, providing systematic guidance for execution and enabling creative forms of expression. For gathering broad, potentially controversial insights and identify relevant questions for deeper examination (step one), we propose an extended version of focus groups: experience focus groups. The detailed investigation of these questions (step two) is realized by altering the method of cultural probes by introducing the experience probes.

Focus groups, a well-known method for qualitative user research within classic human-centered design [8], embody group discussions with the aim to gather insights about the participants' perception, opinions, and attitudes regarding a specific study topic. Thus, they enable for the relevant controversial, multi-perspective input from diverse users at the same time. However, traditional focus groups are not specifically designed to gather insights for experience design. Moreover, the abilities of the moderator are a relevant factor for the success of a traditional focus group. Advanced skills-in understanding group dynamics and steering them-are needed to allow every participant to articulate their personal experiences, requirements, and ideas. In addition, the amount of data acquired during focus groups can be enormous and, thus, requires an extensive and time-consuming data analysis. Thus, we propose extending the concept of the traditional focus group method with an explicit focus on the users' experiences, guidance for the moderation, and the possibility for users to express their experiences visually.

Classical cultural probes enable users to record their answers as "inspirational data" around a given research topic by documenting "beliefs and desires, their aesthetic preferences and cultural concerns" [26,27]—specific experiences, ideas, or interactions-with artifacts such as postcards, cameras, or diaries (in context) over a certain time. In doing so, cultural probes embody a rather creative approach to the given research topic and leave user and designer without explicit instructions for execution. The participants can decide themselves how often and how elaborately they want to reflect on and report their experiences. The method of culture probes itself offers neither guidance to explore the experiences in a systematic way, nor does it provide a clear focus on a specific study topic. Thus, the method results in inspirations for designers rather than structured insights as foundation for experience-based design. Therefore, we propose to extend the concept of cultural probes by augmenting it with a clear structure and tasks to explore hedonic aspects of the users' experiences systematically.

\subsection{Contribution of the Presented Work}

The present work explores how an adapted version of focus groups $[8,28]$ and cultural probes $[26,27]$ can be used in order to address "wicked problems" in user experience research. In this paper, we first describe how we suggest to adapt the two methods to include a clear focus on potentials for positive experiences, enable visual forms of expression and, at the same time, provide guidance for the user researchers with a predominant usability-mindset. We then describe a case study, which shows how the adapted methods can be used in practice. The case study was conducted as a cooperation between experienced user experience researchers and the user research and design team of a company. The aim 
of the case study was to introduce the user experience mindset to the company by conducting the human-centered design process for future digital products and services for families. Finally, we reflect upon the use of the methods and propose directions for further research.

\section{Materials and Methods}

In the following section we first describe three principles, which serve as a base to adapt existing user research methods in order to include a clear focus on potentials for positive experience, enable visual forms of expression and provide guidance for user researchers with a predominant usability mindset. Then we depict the two-step approach for user experience research including a flowchart of the single steps and its expected results. Furthermore, a detailed description of the experience focus groups and the experience probes is provided. Thereby, we describe how those methods address the three principles, provide a clear structure for the individual methods and give instructions how to analyze the data gathered.

\subsection{Principles for Adaption of User Research Methods}

The adaptation of the two methods can be summarized under three different principles, which we already presented in earlier work $[29,30]$.

Principle 1-(Positive) Experience Focus: An important aim of user experience research and design is to detect potentials for positive experience or to create positive experiences for the users during the interaction with interactive products and services. Thus, the design of the adapted methods should support the gathering and analysis of the participants' (positive) experiences and the generation of first ideas for products and services regarding the predefined study topic based on that.

Principle 2-Creative Visualization: The mental model of users and designers of an experience might differ [22] and verbalized words can have multiple meanings. Thus, it seems important to provide support for the users to express their experiences in visual ways, in order to make their experiences graspable for the design team and create objective reference points for discussions about them. To do so, the adapted methods should facilitate a creative mindset, e.g., with a warm-up to support the participants' creative confidence [31,32] in order to install a trustful atmosphere, before the participants are guided to visually express their experiences, opinions and attitudes regarding the study topic. People often hesitate to visualize aspects facing a plain white sheet of paper. Thus, the methods provide, e.g., predefined materials such as templates and stickers or employ tasks, which can be conducted with Lego ${ }^{\circledR}$-bricks. Thereby we build upon the approach of the Lego ${ }^{\circledR}$ Serious Play ${ }^{\circledR}$ method [33], which aims at building metaphors instead of naturalistic images of reality. All these visualizations techniques simplify the "thinking with the hands", which as such can inspire new ideas. Moreover, the visualizations can be used as a base for further discussion, analysis and idea generation. Additionally, through the visualization the participants record their experiences directly, which reduces the effort of documenting for the user researchers.

Principle 3-Systematic Guidance: Especially for design teams with little experience with user research and experience design or a technical or usability-focused background, it seems to be necessary to provide explicit guidance how to carry out the methods [6]. Thus, the methods should incorporate a predefined structuring with specific steps. Each step should include a specific task to answer a particular question or explore a particular aspect of the study topic. Thus, the challenge of defining goals and research questions in user research is broken down into manageable pieces. At the same time, it is assured that the design team does not forget any steps and, following the predefined structure of the method, automatically proceeds in a way that sets the required creative working atmosphere and systematically steers the users towards expressing their experiences. 


\subsection{Two-Step Approach for "Wicked Problems" within User Experience Research}

To address "wicked problems" within user experience design we propose a two-step approach for user experience research as described in Section 1 and depicted in the flowchart in Figure 1.

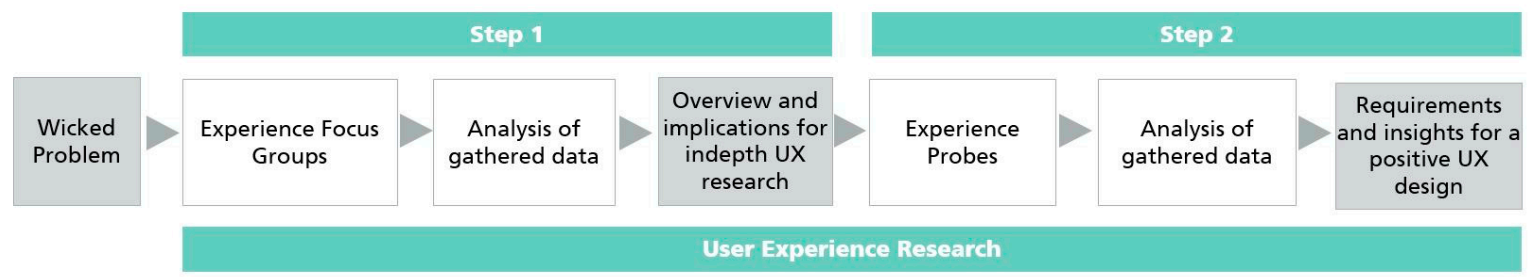

Figure 1. Two-step approach for user experience research to address "wicked problems".

The adapted methods-experience focus groups (step 1a) and the experience probes (step 2a) -are described in individual Sections 2.2.1 and 2.2.2. The methodology for the analysis of both methods (step $1 \mathrm{~b}$ and step $2 \mathrm{~b}$ ) is quite similar and, therefore, represented in Section 2.2.3.

\subsubsection{Experience Focus Groups}

The experience focus group builds upon the basic idea of a traditional focus group and are adapted with the aid of the principles in the following ways:

- Principle 1 and Principle 3: The experience focus groups extend the traditional method by dedicating the predefined phases especially to user experience research. As such, the experience focus group (see Table 2) contains, e.g., phases especially for the gathering of (positive) experiences of the participants (phase 3) and the generation of ideas for positive experiences as a base for following experience design (phase 5).

- Principle 2 and Principle 3: The other phases of the experience focus group (1, 2 and 4) are dedicated to ensure a smooth introduction to a creative mindset and the topic of investigation. Although we propose a specific structuring for the experience focus groups, this structuring can be tailored to individual research questions. The structure consists of different phases and related tasks that can partly be rearranged if needed. Some phases can be omitted if they do not contribute to the research question at hand. However, it is strongly recommended to start with phases 1 "Conducting Warm-Up" and 2 "Setting Reference Points", in order to ensure the smooth introduction to the topic and materials. Phases 3, 4 and 5 can be rearranged or even omitted as required by the topic and research questions for the experience focus group at hand. Each phase of the experience focus group consists of interactive tasks, which enable visual expression of the users' experiences. The interactive tasks can be carried out either by individual participants, small groups or all participants together. Individual tasks are included to assure that all participants can equally take part in the discussion and contribute their experience and ideas. The defined structure with its specific interactive tasks and the change between individual and shared work of the participants supports the moderator of the discussion with time management and steering the group dynamics. Furthermore, while working on the tasks, participants already documented their results in a visual form, which allows the moderator to concentrate fully on the moderation of the experience focus group and significantly reduces the documentation and interpretation time of the generated materials afterwards.

The structure of the experience focus group is displayed in the following Table 2. It also defines the goals, aims, and duration of each specific phase. Durations are estimations for a group size of eight participants and could vary depending on participant numbers. 
Table 2. Structure of experience focus group including the different phases with their goals and aims as well as proposed durations.

\begin{tabular}{cl}
\hline Phase & \multicolumn{1}{c}{ Goals and Aims } \\
$\begin{array}{c}\text { Conducting } \\
\text { Warm Up }\end{array}$ & $\begin{array}{l}\text { Becoming acquainted with one another and the study topic; creation of a } \\
\text { pleasant, trustful, and creative atmosphere. }\end{array}$ \\
$\begin{array}{c}\text { Setting } \\
\text { Reference Points }\end{array}$ & $\begin{array}{l}\text { Individual tasks that help the participants to reflect on their personal views } \\
\text { and current situation regarding the study topic. Thus, all further reflections on } \\
\text { potential positive experiences and product design aspects can be related to } \\
\text { one's own current situation, making discussions more lively and graspable. }\end{array}$ \\
\hline $\begin{array}{c}\text { Gathering } \\
\text { User (Experience) Requirements }\end{array}$ & $\begin{array}{l}\text { Individual or group tasks to identify user requirements for future solutions, } \\
\text { especially potentials for additional positive experiences. }\end{array}$ \\
\hline $\begin{array}{c}\text { Inspiring } \\
\text { Experiential } \\
\text { Impulses }\end{array}$ & $\begin{array}{l}\text { Concretion or defined restriction of the solution space by an impulse } \\
\text { regarding the content of the user experience research study topic (e.g., } \\
\text { presentation of existing product or service solutions) as well as an active } \\
\text { familiarization and experiencing of the presented content for the participants. }\end{array}$ \\
$\begin{array}{c}\text { Generating } \\
\text { Individual or group tasks to develop ideas and visions for positive user } \\
\text { experience design or extend existing solutions for products and services } \\
\text { (within the study topic) regarding positive experiences. }\end{array}$ \\
\hline 30 min
\end{tabular}




\subsubsection{Experience Probes}

The experience probes build upon the traditional method of cultural probes and adapt them with the aid of the principles in the following ways:

- $\quad$ Principle 1 and 3: Structuring the survey into defined phases for more guidance of the users. The single phases of the experience probes involve specific tasks as described above in order to analyze the participants' (positive) experiences and ideas for positive experience design regarding the study topic gradually. The resulting user study with experience probes lasts about one week and is composed of three main steps:

- Introduction workshop (creative mindset, Introduction to visual materials, interactive tasks and general structure)

- $\quad$ Fieldwork (individual/shared execution of interactive tasks)

- Wrap-up workshop (discussion and shared analysis of the users' visualized answers and experiences)

During the fieldwork the participants work daily on the weekly task (phase 0). The other phases 1-7 are dedicated tasks for individual days and follow a predefined order (see Table 3), which allows the participants to concentrate on specific aspects of their or others user experience' regarding the research questions.

- Principle 2: The traditional method of cultural probes already incorporates creative tasks for the participants to express their beliefs, desires and concerns in a creative way. However, the installation of a trustful atmosphere to enable for visual expression of the users' experiences is missing. If the participants do not feel confident with the creative tasks, it is likely that they produce only few results or none at all, which cannot be controlled for in a longitudinal cultural probe study. This shortcoming is therefore addressed by the experience probes by the Introduction Workshop and dedicated phases of the fieldwork to become familiar with the materials and the study topic.

The structure of the experience probes is displayed in the following Table 3. It also defines the goals, aims and duration of each specific phase. Durations are estimations of the accumulated time needed for the task at hand. However, participants can time the fulfillment of the task themselves and also work on the same task at different times throughout one day.

Participants are instructed to document their results with their smartphone using photos, voice recording, and videos. The results of the fieldwork-tasks are communicated daily to the user researchers via instant messenger or e-mail. This ensures that the participants are working daily on their tasks and the user researchers can uncover possible questions or insecurities of the participants about the execution of the experience probes. At the same time, it gives the participants the opportunity to obtain advice or help from the user researchers if needed.

\subsubsection{Analysis of Gathered Data}

To analyze the raw data of the experience focus groups and the experience probes, an analysis workshop of about $3 \mathrm{~h}$ after the execution of each method is proposed. In preparation for the analysis-workshop, the user researchers should document their insights individually directly after the execution of the experience group or right after receiving the materials from the experience probes. This minimizes loss of knowledge, distortion of content and reframing of insights. During the documentation process, they should mainly refer to the materials generated by the participants during the execution of the methods. Therefore, the materials are placed on a table in the middle of a room so that the results are visible and tangible for their individual analysis. 
Table 3. Structure of experience probes including the different phases with their goals and aims as well as proposed durations.

\begin{tabular}{|c|c|c|}
\hline Phase & Goals and Aims & Duration \\
\hline $\begin{array}{c}\text { G } \\
\text { Gathering } \\
\text { User (Experience) Requirements } \\
\text { Encompassing task for the total duration }\end{array}$ & $\begin{array}{l}\text { Repeated (e.g., daily) individual or group task to identify user requirements for future } \\
\text { solutions, including user needs and potentials for additional positive experiences. }\end{array}$ & $10 \mathrm{~min}$ \\
\hline $\begin{array}{c}1 \\
\text { Conducting } \\
\text { Warm Up }\end{array}$ & $\begin{array}{l}\text { Individual task; set up of an informal, creative atmosphere; introduction to the study } \\
\text { topic; identification of positive experiences. }\end{array}$ & $10 \mathrm{~min}$ \\
\hline $\begin{array}{c}2 \\
\text { Defining } \\
\text { Current Experiences }\end{array}$ & $\begin{array}{l}\text { Individual task that allow the participants to familiarize with the study topic and the } \\
\text { status quo of the momentary behavior becomes transparent for the further work on } \\
\text { the study topic during the cultural probes. }\end{array}$ & $30 \mathrm{~min}$ \\
\hline $\begin{array}{c}3 \\
\text { Reflecting } \\
\text { Personal Views }\end{array}$ & $\begin{array}{l}\text { Individual task for the reflection of personal views regarding the study topic as } \\
\text { reference points for the further research process. }\end{array}$ & $30 \mathrm{~min}$ \\
\hline $\begin{array}{l}4 \\
\text { Reflecting } \\
\text { Peers Views }\end{array}$ & $\begin{array}{l}\text { Individual task for the reflection of personal views of other users as reference points } \\
\text { for further study process; gathering of additional insights about the users' view on } \\
\text { and relation to the study topic. }\end{array}$ & $30 \mathrm{~min}$ \\
\hline $\begin{array}{c}5 \\
\text { Imagining } \\
\text { Positive Experiences }\end{array}$ & $\begin{array}{l}\text { Individual task; relevant psychological needs and potential positive experiences are } \\
\text { gathered by describing a hypothetic situation or vision, which includes positive } \\
\text { aspects of the study topic. }\end{array}$ & $30 \mathrm{~min}$ \\
\hline $\begin{array}{c}6 \\
\text { Taking } \\
\text { Experiential Perspectives }\end{array}$ & $\begin{array}{l}\text { Individual task; potential positive experiences and relevant needs are gathered } \\
\text { through user description of hypothetic situations or visions, which includes positive } \\
\text { aspects of the study topic. }\end{array}$ & $30 \mathrm{~min}$ \\
\hline
\end{tabular}


Then, the user researchers conduct an analysis workshop as a group. Thereby, the methods Download your Learnings and Find Themes [34] are applied. The workshop session should be led by an experienced moderator, who is also familiar with those methods. Each of the user researchers gets about ten minutes per research question to report about their personal insights. During those talks, the others are just listening and take notes about their insights from the input on sticky notes. After such an input session, the listeners place and cluster their sticky notes on a wall. The active-listening structure helps to merge the results of the individual analysis efficiently. After all talks, the user researchers stand in front of the wall with the overall results. There, they build clusters, trying to draw patterns and connections in order to answer the posed research questions for the experience probes following an inductive approach.

The main insights of the methods should be summarized visually, e.g., in the form of posters that contain pictures, background details, and major insights about the individual participants. Those posters can serve as an input for the ideation session in order to make the results of the experience probes tangible and lively for the rest of the design team in the following ideation session, who did not take part in the execution and the first analysis of the experiences probes.

\subsubsection{Case Study: A Practical Application and Evaluation of the Two-Step Approach}

The concrete application of the two-step approach of experience focus groups and experience probes has been demonstrated and evaluated in a case study. For this case study, the two-step approach was applied to generate experience-based innovative product and service ideas for the topic of "families and digital life". The study design, methods, and results are described in detail in the next section.

\section{Results}

A case study was conducted to evaluate the feasibility of the adapted user research methods for design teams to enable an experience-centered perspective in their user research and design processes with respect to the three applied principles (positive experience focus, creative visualization, systematic guidance) and the two-step approach. The case study was conducted in cooperation with a telecommunication company who was looking to extend their product and service portfolio for families.

This chapter describes the case study in detail. In Section 3.1, we first outline the concrete methods and task used in the two step-approach (experience focus groups followed by experience probes). In Section 3.2, we describe the results that were obtained from the two methods. Finally, Section 3.3 summarizes the evaluation of the two methods, discussing their feasibility and benefits from the telecommunication company's point of view.

\subsection{Case Study Design and Methods}

The case study was aimed at generating insights about the relevant users' experience considering the topic "families and digital life"—a "wicked problem"—as a base for an innovation process of products and services that can enable positive experiences. The topic is "wicked" because:

- First, the term "family" is not predefined; it can have multiple meanings, e.g., depending on cultural context and social background;

- second, the term 'digital life' is also a rather undefined, general expression, which is open to interpretations;

- $\quad$ and third, there are multiple options to design positive experiences for "families and digital life" due to the nature of experiences and the need for radical innovations.

Thus, the proposed two-step approach for user experience research involving experience focus groups (step 1) and experience probes (step 2) was applied for the "wicked problem" (see Figure 2).

Thereby, the user researchers of the telecommunication company were coached in an iterative feedback-process to design and conduct the methods by themselves, in order to be able to assess how well the three principles were realized in the proposed methods. After the execution of step 1 the gathered 
insights were consolidated and analyzed and served as anchor points to formulate specific user research questions of the experience probes (step 2). The insights of both methods constituted the base for a subsequent ideation process for radical innovative products and services that might enable positive experiences. The subsequent ideation process was conducted as cooperation between our design team and the telecommunication company and is not part of the presented work due do privacy issues.

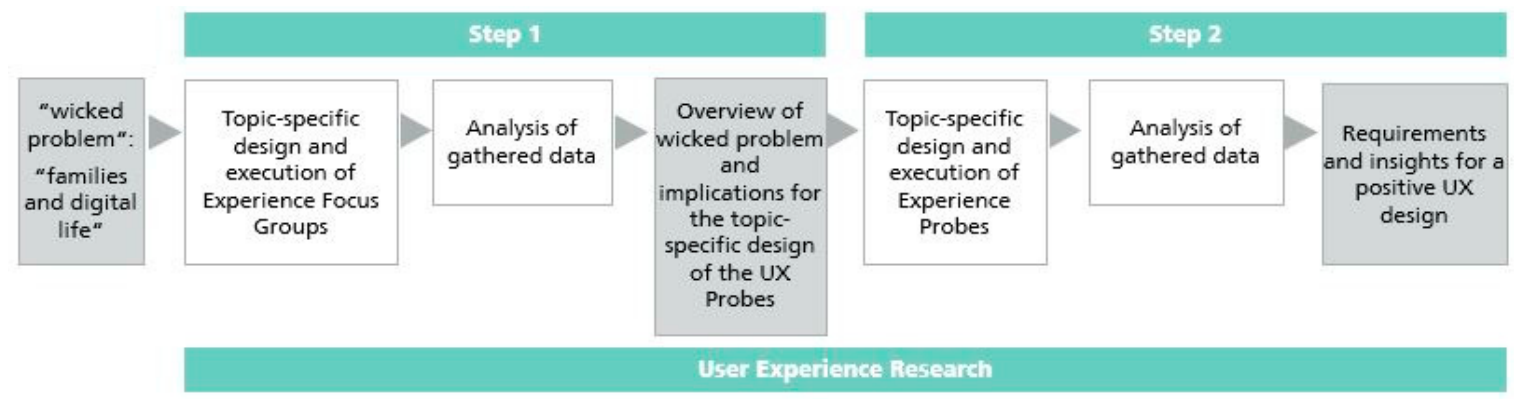

Figure 2. Topic-specific two-step approach for user experience research.

For the experience focus groups and the experience probes participants were recruited via the participant database of the Fraunhofer Institute for Industrial Engineering IAO. An ethical review and approval was not required for the study in accordance with local legislation and institutional requirements. At the beginning of the user studies, participants were informed about the purpose and duration of the study, the anonymity of information processing, and the applicable data protection regulations, as well as the possibility to refuse or terminate participation at any time. Participants then provided their informed consent before taking part in the user studies.

\subsubsection{Step 1: Experience Focus Groups for the "Wicked Problem": "Families and Digital Life"}

Aim: For the case study the experience focus groups were specified and conducted with the following aims:

- $\quad$ to derive potential positives experiences within the merging field of the two topics "families and digital life" and cluster them;

- to understand the different perspectives on the terms "family" and "digital life" as well as their influence on possible positive experiences; and

- gather first ideas and concepts for the experience design of products and services as inspiration for the following ideation process

Participants: Two experience focus groups with 11 participants in total were conducted-experience focus group 1 (two females, two males, age range: 28-51 years) and experience focus group 2 (five females, two males, age range: 26-55 years). All participants frequently used digital devices. They all had an Internet connection at home. Six participants preferably used their smartphone, two participants preferably used their personal computer, two participants equally used their smartphone and personal computer and one participant preferred to use her tablet. Gathering information, watching and reading the news as well as communication issues were the main reasons for the use of the digital devices. We recruited participants that had in general a positive attitude towards technical devices. To assess that we used items of the Affinity for Technology Interaction (ATI) Scale [35]. In order to integrate different perspectives on "families", one participant out of either one of the following family configurations was recruited: "evolution stages of a traditional family" (couple, becoming parents, having children, children moving out/in again, becoming grandparents) and "broader family concepts" (couple without children, single parents, multigenerational home, shared apartment (WG)).

Topic-specific structure, tasks and materials: The topic-specific experience focus groups are displayed in Table 4. Within Table 4, for each phase of the method, specific tasks and associated materials are named. 
Table 4. Phases of topic-specific experience focus groups.

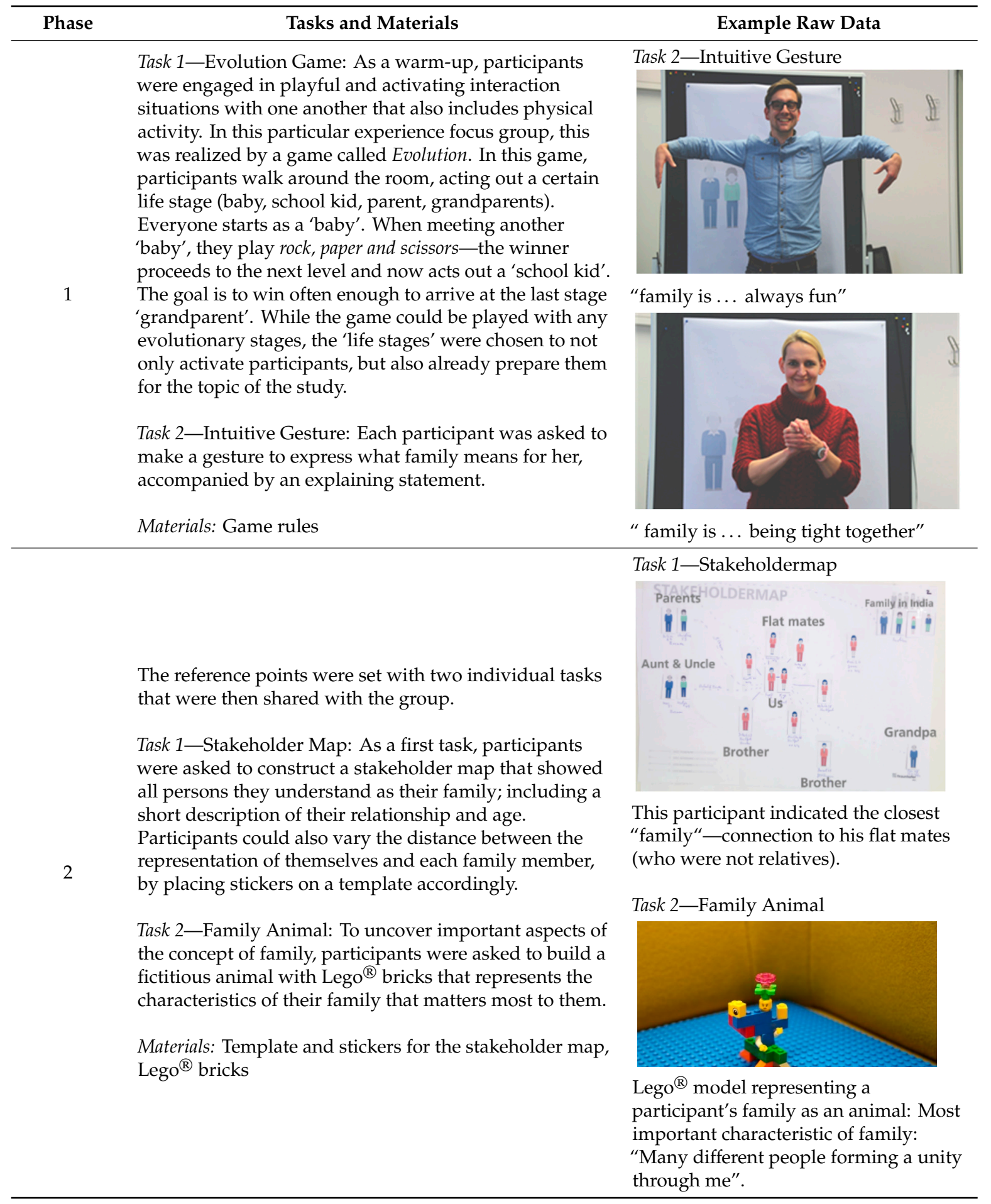


Table 4. Cont.

\begin{tabular}{|c|c|c|}
\hline Phase & Tasks and Materials & Example Raw Data \\
\hline \multirow{6}{*}{3} & & Task 1-Shared (family) Experiences \\
\hline & $\begin{array}{l}\text { The user (experience) requirements were explored from } \\
\text { two different angles, representing the two concepts that } \\
\text { shall ultimately be combined in an interactive product or } \\
\text { service as the goal of this case study: family and use of } \\
\text { digital products. }\end{array}$ & - \\
\hline & $\begin{array}{l}\text { Task 1-Shared family experiences: In a silent } \\
\text { brainstorming participants collected experiences that } \\
\text { bind them together with their family. The experiences } \\
\text { were then shared with the group, clustered on a poster }\end{array}$ & $\begin{array}{l}\text { Shared Family Experience from the } \\
\text { Silent Brainstorming, clustered on a } \\
\text { poster. }\end{array}$ \\
\hline & $\begin{array}{l}\text { and discussed with the focus on elaborating on why } \\
\text { these experiences are perceived as positive. }\end{array}$ & Task 2-Digital Ex \\
\hline & $\begin{array}{l}\text { Task 2-Digital experiences: In a silent brainstorming, } \\
\text { participants wrote down experiences they frequently } \\
\text { have with digital devices and members of their family. } \\
\text { They then put these experiences on a digital journey } \\
\text { map-a poster that outlines the } 24 \text { h of a full day. Thus, } \\
\text { the experiences could be related to specific time points } \\
\text { during a day. Again, the experiences were discussed } \\
\text { among the group. }\end{array}$ & $\exists$ \\
\hline & Materials: Post-its, digital journey map poster & $\begin{array}{l}\text { Digital Journey Map including all } \\
\text { experiences with digital devices } \\
\text { throughout the day. }\end{array}$ \\
\hline \multirow{3}{*}{4} & \multirow{3}{*}{$\begin{array}{l}\text { Task-Vision family life 2050: In groups of three, } \\
\text { participants were instructed to build a model of their } \\
\text { (positive) vision of family life in the year } 2050 \text { using } \\
\text { Lego }{ }^{\circledR} \text { bricks. These models can point towards } \\
\text { potentials of positive experience in future products and } \\
\text { services for families. }\end{array}$} & Task_Vision Family Life \\
\hline & & \\
\hline & & $\begin{array}{l}\text { Lego }{ }^{\circledR} \text { model depicting one group's } \\
\text { vision: increased distance between } \\
\text { family members is bridged by } \\
\text { technology: miniaturized and fast } \\
\text { communication devices; larger screens } \\
\text { for video calls; } 4 \text { D device to cook and } \\
\text { season meals together; communication } \\
\text { robot for "lazy communicators" }\end{array}$ \\
\hline
\end{tabular}

\subsubsection{Step 2: Experience Probes for the "Wicked Problem"- "Families and Digital Life"}

Aim: The experience probes were designed and conducted with three families with the aim to understand the influence of children of different age groups on the perception of positive experiences within the user research topic "families and digital life". Thereby, the focus was set on the occurrence of such (positive) experiences, time dependency, their frequency in daily life, and connection to domestic space. Another aim was to understand common grounds and differences regarding the views of the different family members with respect to the research topic. 
Participants: All three families reported a positive attitude towards digital life and digital devices in general in a screening questionnaire. Furthermore, the recruitment was based on the insights of the experience focus groups - the age of the children within a family constellation:

- $\quad$ Primary school: two adults (female 40 years, male 44 years) three children (6, 9, and 11 years) (two of them in primary school).

- Middle school: two adults (female 40 years, male 46 years), two children (9 and 12 years) (one of them in high school).

- High school and university: two adults (female 50, male 51 years), two children (16 and 22 years) (either working or in university).

Topic specific structures, tasks and materials: Within this work, we put the focus on the description of the fieldwork (see Table 5) as this involves the interactive tasks based on the principles of our approach and leave out the description of the briefing and closing workshop. Table 5 displays the phases of the topic-specific experience probes: Phase 0 describes a daily task, which is carried out on a daily basis during the field phase. Phases 1-6 are additional tasks and conducted on days 1-6 of the field phase, respectively. To account for age-related differences regarding the ability to reflect on and express oneself, some tasks were slightly adapted for children (see Table 5).

Table 5. Phases of the topic-specific experience probes.

\begin{tabular}{|c|c|c|}
\hline Phase & Tasks and Materials & Example Raw Data \\
\hline \multirow{4}{*}{0} & \multirow{3}{*}{$\begin{array}{l}\text { Family Heatmap: Group task for the whole } \\
\text { family to be completed each day throughout } \\
\text { the week. The family members were asked to } \\
\text { track their individual usage of digital devices as } \\
\text { well as their shared usage, which they perceive } \\
\text { as significant experiences. } \\
\text { Our aim was to get an overview over shared } \\
\text { experiences as a family and individual } \\
\text { experiences regarding the domestic space. }\end{array}$} & -Family Heatmap \\
\hline & & 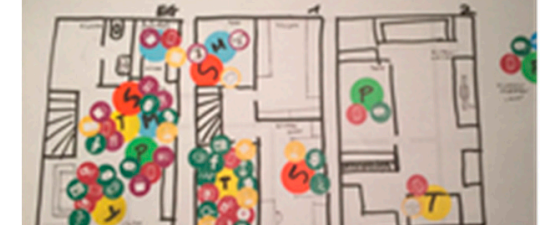 \\
\hline & & \\
\hline & $\begin{array}{l}\text { Materials: Poster with stickers (icons for } \\
\text { activities } \\
\text { and devices, colors and symbols per person } \\
\text { and day). }\end{array}$ & $\begin{array}{l}\text { The family indicated their floor plan of } \\
\text { the house. On this day the main family } \\
\text { activities were in the kitchen and living } \\
\text { room, the daughter was extensively } \\
\text { using her electronic devices also in her } \\
\text { own room. }\end{array}$ \\
\hline \multirow{3}{*}{1} & Experience Snapshots: Individual task to take a & Task-Experience Snapshot \\
\hline & $\begin{array}{l}\text { picture of the first and last person the } \\
\text { participant saw, favorite technical device, } \\
\text { favorite place and most beautiful moment of } \\
\text { the day (adults, children). } \\
\text { Our aim was to set up an informal, creative } \\
\text { atmosphere; and an introduction of the study } \\
\text { topic. Furthermore, we wanted to identify } \\
\text { positive experiences. }\end{array}$ & \\
\hline & $\begin{array}{l}\text { Materials: Personal smartphone camera } \\
\text { (adults, children). }\end{array}$ & $\begin{array}{l}\text { "A sunny day" favorite moment of one } \\
\text { participant. }\end{array}$ \\
\hline
\end{tabular}


Table 5. Cont.

\begin{tabular}{|c|c|c|}
\hline Phase & Tasks and Materials & Example Raw Data \\
\hline \multirow{7}{*}{2} & & Task-Digital Experience (adult) \\
\hline & $\begin{array}{l}\text { Digital Experience: Individual task; document } \\
\text { digital devices used and the frequency } \\
\text { throughout the day. }\end{array}$ & \\
\hline & $\begin{array}{l}\text { - } \quad \text { with the aid of an timeline (adults) } \\
\text { - } \quad \text { draw a picture (children) }\end{array}$ & $\begin{array}{l}\text { The timeline shows the usage of digital } \\
\text { devices throughout the day. "It also } \\
\text { enabled the participants to reflect their }\end{array}$ \\
\hline & $\begin{array}{l}\text { Our aim was for each participant to measure the } \\
\text { own usage of digital devices and get a deeper } \\
\text { understanding of their own digital behavior. }\end{array}$ & own behavior," mentioned a participant. \\
\hline & & Task_-Digital Experience (child) \\
\hline & $\begin{array}{l}\text { Materials: Timeline template with a legend to } \\
\text { track their usage of digital devices (adults). } \\
\text { Piece of paper and colored pens (children). }\end{array}$ & 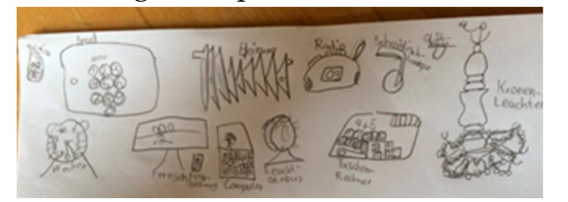 \\
\hline & & $\begin{array}{l}\text { Drawing of one child showing the } \\
\text { devices used during the day. Even } \\
\text { devices, such as the heating system, } \\
\text { were mentioned. }\end{array}$ \\
\hline \multirow[t]{2}{*}{3} & $\begin{array}{l}\text { Personal Role of technology: "Which role does } \\
\text { technology play in your life?" } \\
\text { Individual task, participants were asked to } \\
\text { reflect their personal digital (daily) life. } \\
\text { Our aim was the reflection of personal views on } \\
\text { the study topic. }\end{array}$ & $\begin{array}{l}\text { Task-Personal view of technologies' } \\
\text { role in life }\end{array}$ \\
\hline & Materials: Small bag of Lego ${ }^{\circledR}$ bricks & $\begin{array}{l}\text { Lego }{ }^{\circledR} \text { model displaying the own } \\
\text { perception of technology used. Digital } \\
\text { devices are understood as helpful } \\
\text { devices to organize the family life, } \\
\text { therefore, it is easier to keep a good } \\
\text { overview (symbolized by the telescope). }\end{array}$ \\
\hline 4 & $\begin{array}{l}\text { Role of Technology for Peers: "How do other } \\
\text { family members interact/ behave with } \\
\text { technology?" } \\
\text { Individual task, participants were asked to } \\
\text { reflect how other family members use their } \\
\text { digital devices. } \\
\text { Our aim was to reflect the own perception of } \\
\text { the behavior with digital devices of other family } \\
\text { members. Through the change of perspective } \\
\text { the own perception should be broadened. } \\
\text { Materials: Lego }{ }^{\circledR} \text { bricks }\end{array}$ & $\begin{array}{l}\text { Task-Peers view of technologies' role in } \\
\text { life } \\
\text { Lego }{ }^{\circledR} \text { model displaying how an adult } \\
\text { perceived their teenage } \\
\text { child-self-isolated through their } \\
\text { smartphone usage. }\end{array}$ \\
\hline
\end{tabular}


Table 5. Cont.

\begin{tabular}{|c|c|c|}
\hline Phase & Tasks and Materials & Example Raw Data \\
\hline \multirow{6}{*}{5} & \multirow{5}{*}{$\begin{array}{l}\text { Taking Time Off: Individual task to write and } \\
\text { draw (adults) or draw (children) a story about a } \\
\text { family day trip. } \\
\text { Our aim was to gather potential positive } \\
\text { experiences through the description of a } \\
\text { hypothetic situation or vision, which includes } \\
\text { positive aspects of the study topic. }\end{array}$} & Task-Taking Time Off (adult) \\
\hline & & Extursioustag: \\
\hline & & 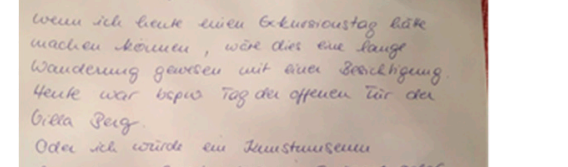 \\
\hline & & 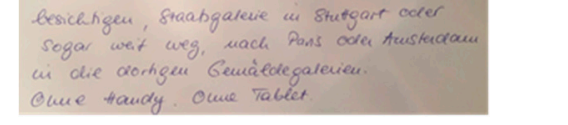 \\
\hline & & $\begin{array}{l}\text { Description of a family day trip. } \\
\text { Interesting result, the participant was }\end{array}$ \\
\hline & Materials: Piece of paper and colored pens & $\begin{array}{l}\text { wishing for no digital devices during } \\
\text { the day. Instead they wanted to spend } \\
\text { time together visiting a museum or } \\
\text { going on a long hike. }\end{array}$ \\
\hline \multirow{4}{*}{6} & Taking Experiential Perspectives: & Task-If you were child again ... (adult) \\
\hline & $\begin{array}{l}\text { "If you were a child again-how would look } \\
\text { your room today?"-draw your desired room } \\
\text { (adult) } \\
\text { "When I grow up ... "- -draw or build a Lego }{ }^{\circledR} \\
\text { model (child) }\end{array}$ & (a) \\
\hline & $\begin{array}{l}\text { Our aim was to experience the topic from the } \\
\text { perspective of a different family member. }\end{array}$ & (i) \\
\hline & $\begin{array}{l}\text { Materials: Piece of paper and colored pens } \\
\text { (adults), piece of paper and colored pens, } \\
\text { Lego }^{\circledR} \text { (children). }\end{array}$ & $\begin{array}{l}\text { Drawing of an adult showing how the } \\
\text { desired kids' room would look like. } \\
\text { Only an Internet radio is mentioned } \\
\text { everything else is analogue. }\end{array}$ \\
\hline
\end{tabular}

\subsection{Case Study Results}

\subsubsection{Step 1: Results of Topic-Specific Experience Focus Groups}

Example data gathered for the single phases of the conducted experience focus groups are displayed in Table 4. Example experiences clusters drawn from the experience focus groups are commitment, reassurance, transmission and sharing. Regarding first ideas and concepts for the experiences design as well as the influence factors on the perception of positive experiences within the given "wicked problem", the insights yielded that positive "family" experiences and their perception within the context of digital life are strongly dependent on the involvement of children as well as their respective age. These insights served as a starting point for the concept and the formulation of the specific tasks for the experience probes.

\subsubsection{Step 2: Results of Topic-Specific Experience Probes}

Example data gathered for the single phases of the conducted experience probes are displayed in Table 5. The insights gathered and drawn from those datasets served as base for the extension and refinement of the clustered positive experiences of the experience focus groups. Especially, insights considering the multi-perspective view on the same "digital family" experiences have to be pointed out here. Adults and children perceive the digital family life quite differently, which needs to be reconsidered, when designing products and services for families. For example, the younger children who took part in the study grew up with digital devices as an essential part of their home and leisure activities. They take them for granted and integrate them in their daily lives more naturally than the older children or parents, which also influences the perception of positive experiences with digital 
environments and devices. The insights were summarized in three family posters, which served as input for the subsequent ideation session. The results of the ideation session were three concepts for products and services within the topic of "families and digital life":

- Positive Experience-Reassurance: Product to enhance the feeling of connection and trust in family relationships.

- Positive Experience-Sharing: Shared family moments: Product to enable shared experiences for families.

- Positive Experience-Sharing: Shared family decision: Service to enhance decisions within families, which every family member perceives as positive.

\subsection{Case Study Evaluation: Practical Application of Experience Focus Groups and Experience Probes}

In order to gather first insights about the feasibility, potential benefits, as well as opportunities of improvement of the experience focus groups and experience probes for corporate design team, we chose a formative approach of evaluation. Thus, we conducted semi-structured interviews with two members (interviewee 1, female, 42 years; interviewee 2, female, 38 years) of the user research and design team of the company. The interviews were conducted in English via a video-conference tool with the interviewee, the interviewer, and a note-taker. The interviewees were inquired about their perceptions regarding:

- The feasibility and efficiency of the two adapted methods within the context of user experience research; and

- the usefulness of the methodological approach based on the three principles to find radical innovative ideas for products and services.

Regarding the new approach to user research methods, they stated that the enhanced methods with their provided guidance and materials were very helpful and effective regarding the gathering of valuable insights: "It's a good way to go beyond the formal level of the participants to approach the real values and emotions." (interviewee 1). Within that respect, they were excited about the openness of the participants regarding the study topic and their personal experiences. Moreover, they found that all participants were more actively involved than in their usual focus groups and, thus, the group dynamic was rather positive. Furthermore, they thought, that it was a "more progressive approach" - not asking users directly what they need, but instead let them visualize their opinions and views, which yielded richer and more unbiased insights. Furthermore, they stated that it was good that the user research methods were conducted in close cooperation with us because they think that just the rather abstract description of the structure of the methods would be not sufficient to achieve the same results as in the given case study.

Additionally, they found, that the approach was good to find innovative and disruptive ideas for positive family experiences, which are now used for the company's new product and service portfolio. The family posters displaying the analyzed results are still displayed in the corridors of the researchers' offices. They are used as inspiration and to go deeper during the creation of ideas in ideation sessions.

The results of the conducted user research methods served also as a base for the creation of a reference set of categories considering "families and digital life". A category consists of several positive experiences for "families and digital life" (examples: commitment, reassurance, transmission, sharing, pleasure, etc.). The reference set itself serves as a model for the user experience design team as well as the marketing team to develop, adjust, and communicate existing and future products and services for families. Within that respect it can, e.g., be applied during user experience research to identify relevant user experience requirements, in the conception phase for ideation processes or for the evaluation and comparison of concepts or existing products and services. 


\section{Discussion}

In this paper, we proposed adjusted versions of the well-established user research methods focus groups and cultural probes, in order to tailor them to the specific needs and focus of experience-based design, especially in the context of solving "wicked design problems". The results are experience focus groups and experience probes, which augment the traditional methods with new structuring, materials and tasks based on the three principles experience focus, creative visualization, and systematic guidance. We presented a detailed description of a two step-approach for applying these methods as well as a case study that was conducted in cooperation with a telecommunication company and illustrates how the methods were applied to enable an experience-centered perspective on the topic of "families and digital life". The case study demonstrated how the methods make use of the three principles experience focus, creative visualization, and systematic guidance in order to enable the experience-focused design of new products or services, and provides an overview of their potential benefits for experience design. Post-study interviews with representatives of the company revealed valuable insights about their usefulness for practical user experience design.

The case study shows that the experience focus groups and experience probes promote an experience perspective in user research and design processes. Based on the interviews with company representatives, it can also be concluded that they can support the transition from a usability-focused mindset of the design team to a more hedonic, experience-focused perspective in a corporate environment. The members of the corporate user research and design team stated that the methods were very efficient and helpful to get the participants to talk openly about their emotional experiences in their personal family life. They also highlighted how the methods supported the active, creative involvement of the participants in the design process, which was very different from their experience with previous user research processes. In addition, they reported that the two-step approach enabled them to efficiently gather valuable insights about potential positive experiences for the "wicked problem", which constitute the base for at least three relevant product and service concepts for the company. Furthermore, the insights of the methods founded the basis of a reference set of categories of positive experiences for families, which is similar to the experience categories proposed by Zeiner et al. [16,18]. This reference set is now frequently used by the company's design and marketing teams for further experience-based product and service innovation. In addition, the family posters-the visualized insights of the experience probes-are still displayed in the company and serve as input to enable an experience-centered perspective when designing products and services.

Although the case study and interviews with the company's design team revealed many benefits of applying experience focus groups and experience probes, there are also some limitations to the two methods. The presented case study can only be regarded as a first step towards user research methods, which deliberately focus on the promotion of experience-based, hedonic product, and service innovation.

Thus far, the three principles have only been applied to these two methods and evaluated in a single case study. Furthermore, we gathered just first formative feedback about the feasibility of the two-step approach in corporate environments. To truly demonstrate their general value for experienceand hedonic-focused design, the principles will have to be applied to different user research methods and used in a number of studies.

Still, as the case study was employed as a qualitative evaluation and proof-of-concept [36], it yielded rich insights about the applicability of the three principles to enhance existing user research methods and how we might adjust methods on behalf of them for other "wicked problems" in the future. For instance, we learned in our coaching and feedback loop with the company's design team that designing the tasks for the method phases and conducting the two-step approach can sometimes be challenging - especially when employing the methods for the first time. Thus, for future application of the methods, the aspect of the principle systematic guidance should be even more stressed, in order to enable an independent study execution. Therefore, we plan to enhance the description of the methods with more concrete instructions for actions, preformulated tasks, and templates that just need to be adapted for the respective 
study topic. Additionally, hints for the moderation and coordination of the methods as proposed in $[10,11,22]$, and their clear step-by-step instruction seem to be useful. Especially details on how to proceed during the preparation of both methods could ease their applicability for other "wicked problems". In order to do so, we plan to conduct more case studies focusing on two different aspects. On the one hand, we want to extract and formalize insights as well as best practices-regarding the design, the preparation and the conduction of the two-step approach. On the other hand-to further proof the validity of the methods-we want to compare the application of the original and the enhanced methods for one "wicked problem". For all this future work, we plan to gather feedback not only from the respective design team but also directly from the users, the participants of the method. This enables valuable insights on the users' experience of the execution and their perception of the two-step approach considering participation and outcome. Thus, to achieve a more diverse viewpoint on the applicability of the methods for real-world "wicked problems".

Additionally, one might argue that the interviews could be prone to social bias. The authors of this work acted in a double-role: They coached the design team to conduct the methods and were also the interviewers who conducted the method evaluation. However, we can discard this concern, since the company still makes use of the results and the methods, without the support of the coaching team. This shows that the application of the two-step approach is a valuable and sustainable addition to the user research methods of the company's design team, leading to relevant experience-based product and service innovations.

We regard the application of the second principle creative visualization as a necessity to enhance existing user research methods. However, this might exclude special user groups-especially participants with visual impairments. Right now, this is a limitation for the application of the methods. Respectively, future work should be done on how to enable user groups with special needs to express their experiences in a creative and, for the researchers, unambiguous way. The application of tangible Lego ${ }^{\circledR}$-bricks for visualization might be the first step in the right direction.

In summary, the augmentation of existing methods with the three principles seems to be a promising approach to enable an experience-centered perspective in user research and design. For future work, we plan to apply the generic principles to other user (experience) research methods, such as UX concept exploration [3] and interview methods. Furthermore, we will also evaluate whether the order of the two steps is mandatory to address "wicked problems" and which other combinations of methods could be used to promote the experience-centered design of innovative products and services.

Author Contributions: Conceptualization: A.E.K., K.P., and N.F.; investigation: A.E.K., K.P., N.F., and B.F.; methodology: A.E.K., K.P., and N.F.; project administration: A.E.K.; writing一original draft: A.E.K., K.P., N.F., and B.F.; writing-review and editing: A.E.K., K.P., N.F., and B.F. All authors have read and agreed to the published version of the manuscript.

Funding: This research received no external funding.

Acknowledgments: The authors thank Orange ${ }^{\mathrm{TM}}$ for the real-world "wicked problem" and the possibility to conduct a case study as part of a bilateral project between Orange $\mathrm{e}^{\mathrm{TM}}$ and the Fraunhofer Institute.

Conflicts of Interest: The authors declare no conflict of interest.

\section{References}

1. Kahneman, D. Others objective happiness. Well Found. Hedonic Psychol. 1999, 3, 1-23.

2. Spath, D.; Peissner, M.; Sproll, S. Methods from neuroscience for measuring user experience in work environments. In Proceedings of the International Conference on Applied Human Factors and Ergonomics (AHFE 10), Miami, FL, USA, 17-20 July 2010; USA Publishing: West Lafayette, IN, USA, 2010.

3. Fronemann, N.; Peissner, M. User Experience Concept Exploration: User Needs as a source for innovation. In Proceedings of the 8th Nordic Conference on Human-Computer Interaction Fun, Fast, Foundational-NordiCHI '14, Helsinki, Finland, 26-30 October 2014; ACM Press: Helsinki, Finland, 2014; pp. 727-736.

4. Hassenzahl, M. The hedonic/pragmatic model of user experience. UX Manif. 2007, 10-14. Available online: https://www.academia.edu/2880396/The_hedonic_pragmatic_model_of_user_experience (accessed on 23 July 2020). 
5. Laib, M.; Burmester, M.; Ficano, C.; Fronemann, N.; Kolb, B.; Krüger, A.; Quesseleit, M.-L.; Schippert, K.; Shinkarenko, M. User Experience bei Softwareanbietern. In Mensch \& Computer 2015 Proceedings; De Gruyter Oldenbourg: Berlin, Germany, 2015; pp. 93-102.

6. Krüger, A.E.; Fronemann, N.; Peissner, M. Das kreative Potential der Ingenieure-menschzentrierte Ingenieurskunst. In Proceedings of the Stuttgarter Symposium für Produktentwicklung (SSP 2015) Entwicklung smarter Produkte für die Zukunft, Stuttgart, Germany, 19 June 2015; pp. 1-10.

7. Rittel, H.W.; Webber, M.M. Wicked problems. Man-Made. Futur. 1974, 26, 272-280.

8. Morgan, D.L. Focus groups. Annu. Rev. Sociol. 1996, 22, 129-152. [CrossRef]

9. Kujala, S.; Minge, M.; Pohlmeyer, A.; Vogel, M. Temporal Aspects of User Experience: Models and Methods Beyond a Single Use Situation. 2012. Available online: https://www.semanticscholar.org/paper/Temporal-aspectsof-user-experience\%3A-Models-and-a-Kujala-Minge/b05d0fd4166dea4ed59407552180ef4663ef3be5 (accessed on 23 July 2020).

10. Rubin, J.; Chisnell, D.; Spool, J. Handbook of Usability Testing: How to Plan, Design, and Conduct Effective Tests; John Wiley \& Sons Inc.: Hoboken, NJ, USA, 2011; ISBN 978-0-470-38608-8.

11. Holtzblatt, K.; Wendell, J.B.; Wood, S. Rapid Contextual Design: A How-to Guide to Key Techniques for User-Centered Design; The Morgan Kaufmann series in interactive technologies; Elsevier/Morgan Kaufmann: San Francisco, CA, USA, 2005; ISBN 978-0-12-354051-5.

12. Diefenbach, S.; Hassenzahl, M. Psychologie in der nutzerzentrierten Produktgestaltung; Springer: Berlin/Heidelberg, Germany, 2017.

13. Yoon, J.; Desmet, P.M.; Pohlmeyer, A.E. Embodied typology of positive emotions: The development of a tool to facilitate emotional granularity in design. In Proceedings of the IASDR 2013: Proceedings of the 5th International Congress of International Association of Societies of Design Research “Consilience and Innovation in Design", Tokyo, Japan, 26-30 August 2013; International Association of Societies of Design Research: Regensburg, Germany, 2013.

14. Rafael, C.; Dorian, P. Wellbeing Determinant Cards. Posit. Comput. 2015. Available online: http: //www.positivecomputing.org/p/were-pleased-to-share-some-of-tools-and.html (accessed on 23 July 2020).

15. Kahneman, D.; Krueger, A.B.; Schkade, D.A.; Schwarz, N.; Stone, A.A. A survey method for characterizing daily life experience: The day reconstruction method. Science 2004, 306, 1776-1780. [CrossRef] [PubMed]

16. Zeiner, K.M.; Laib, M.; Schippert, K.; Burmester, M. Identifying Experience Categories to Design for Positive Experiences with Technology at Work. In Proceedings of the 2016 CHI Conference Extended Abstracts on Human Factors in Computing Systems, San Jose, CA, USA, 7-12 May 2016; pp. 3013-3020.

17. Laib, M.; Burmester, M.; Zeiner, K. Erlebnispotentialanalyse-Mit Systematik zu positiven Erlebnissen. In Mensch E Computer - 2017 Usability Prof.; Gesellschaft für Informatik e.V.: Regensburg, Germany, 2017.

18. Zeiner, K.M.; Henschel, J.; Schippert, K.; Haasler, K.; Laib, M.; Burmester, M. Experience Categories in Specific Contexts-Creating Positive Experiences in Smart Kitchens. In Proceedings of the International Conference of Design, User Experience, and Usability; Springer International Publishing AG: Basel, Switzerland, 2018; pp. 306-324.

19. Burmester, M.; Zeiner, K.; Schippert, K.; Platz, A. Creating positive experiences with digital companions. In Proceedings of the Extended Abstracts of the 2019 CHI Conference on Human Factors in Computing Systems, Glasgow, UK, 4-9 May 2019; pp. 1-6.

20. Zeiner, K.M.; Laib, M.; Schippert, K.; Burmester, M. Das Erlebnisinterview-Methode zum Verständnis positiver Erlebnisse: Praktische Einführung und Diskussion von Implikationen zur UX-Gestaltungspraxis. In UP 2016; Gesellschaft für Informatik e.V. \& German UPA e.V.: Aachen, Germany, 2016.

21. Norman, D. The Design of Everyday Things Revised and Expanded Edition; Basic Books: New York, NY, USA, 2013; ISBN 978-0-465-07299-6.

22. Sanders, L.; Stappers, P.J. Convivial Design Toolbox: Generative Research for the Front End of Design; BIS: Amsterdam, The Netherlands, 2012; ISBN 978-90-6369-284-1.

23. Hassenzahl, M. User experience (UX): Towards an experiential perspective on product quality. In Proceedings of the IHM, Metz, France, 2-5 September 2008; Volume 8, pp. 11-15.

24. Hassenzahl, M. Experience design: Technology for all the right reasons. Synth. Lect. Hum. Centered Inform. 2010, 3, 1-95. [CrossRef] 
25. Janssen, D.; Pollmann, K.; Fronemann, N.; Blank, D. Enabling SMEs to Conduct User Research: Experience with and Adaption of UX Concept Exploration. In Proceedings of the International Conference on Applied Human Factors and Ergonomics; Springer: Basel, Switzerland, 2019; pp. 445-456.

26. Gaver, B.; Dunne, T.; Pacenti, E. Design: Cultural probes. Interactions 1999, 10, 21-29. [CrossRef]

27. Gaver, W.W.; Boucher, A.; Pennington, S.; Walker, B. Cultural probes and the value of uncertainty. Interact 2004, 11, 53-56. [CrossRef]

28. Kitzinger, J. Qualitative research: Introducing focus groups. BMJ 1995, 311, 299-302. [CrossRef] [PubMed]

29. Krüger, A.E.; Peissner, M.; Fronemann, N.; Pollmann, K. BUILDING IDEAS: Guided Design for Experience. In Proceedings of the 9th Nordic Conference on Human-Computer Interaction; ACM: New York, NY, USA, 2016; pp. 115:1-115:6.

30. Krüger, A.E.; Kurowski, S.; Pollmann, K.; Fronemann, N.; Peissner, M. Needs profile: Sensitising Approach for User Experience Research. In Proceedings of the 29th Australian Conference on Computer-Human Interaction-OZCHI '17, Brisbane, Australia, 28 November-1 December 2017; ACM Press: Brisbane, Australia, 2017; pp. 41-48.

31. Kelley, T.; Kelley, D. Creative Confidence: Unleashing the Creative Potential within Us All; William Collins: London, UK, 2013; ISBN 978-0-00-751797-8.

32. Plattner, H.; Meinel, C.; Weinberg, U. Design-Thinking; Springer: Berlin/Heidelberg, Germany, 2009.

33. Kristiansen, P.; Rasmussen, R. Building a Better Business. Using the Lego Serious Play Method; Wiley: Hoboken, NJ, USA, 2014; ISBN 978-1-118-83245-5.

34. IDEO. Commercial the Field Guide to Human-Centered Design; Design Kit, 2015; Available online: https: //www.designkit.org/resources/1 (accessed on 23 July 2020).

35. Franke, T.; Attig, C.; Wessel, D. Assessing Affinity for Technology Interaction-The Affinity for Technology Interaction (ATI) Scale. Unpublished manuscript. 2017.

36. Myers, M.D. Qualitative Research in Business and Management; Sage Publications Limited: New York, NY, USA, 2019.

(C) 2020 by the authors. Licensee MDPI, Basel, Switzerland. This article is an open access article distributed under the terms and conditions of the Creative Commons Attribution (CC BY) license (http://creativecommons.org/licenses/by/4.0/). 